\title{
Globe
}

Revue internationale d'études québécoises

\section{Définir des modernités hybrides. Entre société, patrimoine, savoir, pouvoirs contemporains et culture autochtones}

\section{Daniel Chartier}

Volume 8, numéro 1, 2005

Les modernités amérindiennes et inuite

URI : https://id.erudit.org/iderudit/1000891ar

DOI : https://doi.org/10.7202/1000891ar

Aller au sommaire du numéro

Éditeur(s)

Globe, Revue internationale d'études québécoises

ISSN

1481-5869 (imprimé)

1923-8231 (numérique)

Découvrir la revue

Citer ce document

Chartier, D. (2005). Définir des modernités hybrides. Entre société, patrimoine, savoir, pouvoirs contemporains et culture autochtones. Globe, 8(1), 11-16.

https://doi.org/10.7202/1000891ar d'utilisation que vous pouvez consulter en ligne. 


\title{
Introduction
}

Définir des modernités hybrides. Entre société, patrimoine, savoir, pouvoirs contemporains et culture autochtones

\author{
Daniel Chartier \\ Université du Québec à Montréal
}

Poser la question de la modernité en termes de culture, de société, de savoir, de pouvoir et de patrimoine amérindiens et inuits force à considérer de front les modalités de la question et les possibilités de sa réponse. Parce qu'elle a le mérite d'éviter les pièges du regret d'un mythique passé ou encore d'une culpabilité historique - dont les études sur les Autochtones sont rarement exemptes -, l'idée de la modernité atteint à l'essentiel et au droit inaliénable des peuples et des cultures à l'historicité. Ce qui est ici en jeu est moins le compte et la description des marques de la civilisation moderne dans des cultures fixées par une imagologie coloniale que la tension qui existe entre le droit de définir des modernités qui puissent intégrer histoire et traditions, qui se définissent elles-mêmes comme des modernités bybrides.

La lecture des articles qui composent le présent numéro convainc que les changements en cours chez les nations amérindiennes du Québec et chez les Inuits s'inscrivent d'abord sur un mode culturel, social et économique, bien que la source du mouvement soit géopolitique. Les modifications physiques du territoire, qu'elles soient issues de l'exploitation forestière, du tourisme ou des aménagements hydroélectriques, ont induit une réaction politique. Celle-ci a conduit à la fois à la signature de nouveaux traités - la Convention de la Baie-James et du Nord québécois en 1975, la Paix des Braves en 2002-, à des

Daniel Chartier, - Introduction. Définir des modernités hybrides. Entre société, patrimoine, savoir, pouvoirs contemporains et culture autochtones -, Globe. Revue internationale d'études québécoises, vol. 8, n 1, 2005. 
programmes - dont le Programme d'aide aux chasseurs - et à une prise de conscience de la nécessité, pour chacun des peuples, de se définir de manière originale, souvent dans une modernité hybride qui cherche à concevoir le rapport social et culturel en tenant compte à la fois du patrimoine (matériel, immatériel) et des problématiques contemporaines.

Louis-Edmond Hamelin défend en ouverture de ce dossier la nécessité, pour le Québec, de conceptualiser sa position géopolitique en fonction d'un axe sud/nord, dans une démarchè quì s'inspire de l'idéologie de la coexistence et qui vise, selon l'auteur, à réaliser " un projet panQuébec de territorialité ". Malgré l'importance de la signature du traité de 1975, qui se veut une " reconnaissance d'une nordicité autochtoniste ", Hamelin constate avec désarroi que " peu de personnes envisagent un Québec total avec une charge émotive équivalente ", ce qui pose des problèmes de gouvernance. Le Québec laurentien, "initialement autochtone, principalement francophone, partiellement anglophone et depuis peu allophone ", n'occupe que le tiers du territoire, bien que cette partie s'est souvent prise pour l'ensemble du Québec. Au nord s'étend un territoire presque uniquement défini par son autochtonie, lié politiquement au Québec depuis 1912, mais toujours "considéré très peu utile " malgré quelques initiatives d'aménagement et d'exploitation. Pour Hamelin, le Québec doit arriver à se concevoir dans sa totalité, dans le respect culturel et social des parties et dans un mode de gouvernance original, qui n'existe pas encore, mais qui pourrait devenir, s'il est suffisamment ample et souple, la base d'un projet interculturel de refondation d'une nation polyethnique.

Le souhait d'une meilleure coexistence ne peut toutefois passer sous silence les difficultés de la situation présente des Amérindiens et des Inuits. Jean-François Létourneau rappelle l'état de dépendance créé depuis le $\mathrm{xIX}^{e}$ siècle par le cadre légal fédéral (notamment la Loi sur les Indiens) et ses conséquences sur la vie quotidienne des communautés. Un rapport récent de la Commission des droits de la personne et des droits de la jeunesse du Québec indique que les Autochtones ne peuvent " prendre part activement au développement socio-économique de leur communauté - et que cela "favorise l'érosion de leur identité, de leur langue et de leur culture *. Une fois encore, le pouvoir et la culture paraissent liés. Parmi les solutions envisagées, la Commission du Nunavik, chargée par les Inuits du Québec "d'analyser les différentes voies menant à l'autonomie politique ", propose bon nombre de mesures 
culturelles qui touchent aux modes de diffusion contemporains : "la conception d'une Charte de la langue et de la culture inuites, la prédominance de l'inuktitut dans les activités du gouvernement, l'augmentation du temps d'antenne consacré à cette langue, une présence plus importance dans les médias écrits, etc. "Si le contexte politique ne peut être compris seul - les considérations écologiques menaçant aussi les cultures et les pratiques inuites -, il manifeste cependant, pour bien des Inuits d'aujourd'hui, une manière de reprendre en main un développement qui leur a échappé depuis des décennies.

En comparant la situation des Inuits au Québec avec celle des Corses, mais aussi avec celles d'autres peuples autochtones, LouisJacques Dorais constate que par des arrangements administratifs et légaux, dont la Convention de la Baie-James et du Nord québécois, les Inuits ont réussi à s'intégrer à la société et à conserver leur langue - $96 \%$ des locuteurs parlaient toujours ou surtout l'inuktitut à la maison. au Nunavik en 2001. Il pose l'hypothèse qu'une société minoritaire et plurilingue, comme l'est le Québec, bien qu'elle ait toujours.des tendances impérialistes envers ses minorités, favorise les revendications et pouvoirs autochtones.

En s'attardant à la contribution des Hurons-Wendat au développement de l'industrie du cuir aux $\mathrm{xxx}^{e}$ et $\mathrm{xx}^{e}$ siècles, Julie-Rachel Savard découvre la faiblesse des études qui analysent le rôle des Autochtones dans l'économie, outre quelques ouvrages qui reconduisent les clichés sur les guides et les chasseurs. Bien sûr, la situation actuelle des Amérindiens et des Inuits est partout déplorable : le recensement de 1995 révélait que le revenu d'un Autochtone ne représentait que $56 \%$ de celui des autres citoyens au Canada. Cependant, Savard écrit que, depuis les débuts de la colonie, les Amérindiens ont joué un rôle déterminant dans le commerce et l'industrie. Malgré les difficultés causées par leur assujettissement, les Hurons-Wendat démontrent comment l'adaptabilité à l'économie a permis de réactualiser leur a culture de manière à adapter [leur] mode de vie aux nouvelles conditions .

1. Le lecteur constatera que nous avons respecté le souhait de certains auteurs de ce numéro de conserver une graphie invariable pour * Inuit • (* Inuk *, au singulier). Partout ailleurs, nous avons toutefois tenu compte de la recommandation de l'Office québécois de la langue française et accordé en genre et en nombre l'adjectif et le nom * Inuit •, et employé le terme * inuktitut •. 
Pour Katia Iankova, le tourisme représente aujourd'hui une réelle possibilité de réhabilitation socio-économique et culturelle pour les communautés autochtones. La plupart des études soulignent en effet qu'il joue " un rôle catalyseur dans la valorisation de la culture et de l'histoire des Autochtones ^. D'abord déterminé sous un mode folklorique et coloniạl, le tourisme amérindien et inuit apparaît cependant à terme comme un véritable contact interculturel permettant une renaissance d'activités traditionnelles qui deviennent à rebours objets de fierté pour les membres des communautés. Par contre, ce tourisme semble encore largement destiné aux clientèles européennes, les Québécois lui démontrant peu d'intérêt.

L'aménagement politique et économique ne saurait faire oublier les différences qui séparent les cultures sudistes de celle des Inuits, et qui ont parfois une incidence profonde sur la vie en société. Guy Bordin défend l'idée qu'il existe un déphasage entre les représentations du temps inuites et celles qui leur ont été imposées par le calendrier grégorien des administrations commerciales et coloniales. Ce décalage aurait "créé des tensions entre les pratiques traditionnelles et les nombreuses contraintes imposées *, mais aussi un broullage des * modes de repérage et de division du temps *. À l'aide d'une étude sur le terrain, il démontre que les communautés ont cependant réussi à produire a un système hybride de gestion du temps * dont l'application varie selon les individus et les situations. Marquée par le pragmatisme, la culture inuite a réussi à incorporer certains interdits religieux - comme le repos obligé le dimanche - tout en respectant les rythmes saisonnier du Nord et traditionnel de la chasse. Bordin remarque que la gestion hybride du temps produit aujourd'hui deux types de réactions chez les Inuits : * certains ont pu établir leur mode de fonctionnement personnel et social dans [la] coexistence des temps *, tandis que "d'autres, au contraire, sont plus hésitants sur la conduite à tenir et se trouvent souvent en déphasage général par rapport à ceux qui travaillent *. It s'ensuit une inégalité sociale et économique qui devra trouver une solution originale et particulière à chaque communauté.

Pour Denis Gagnon, une même hybridité caractérise le métissage religieux à l'œuvre chez les Mamit Innuat, ce qui conduit à une certaine invalidation de l'opposition entre les concepts de tradition et de modernité. La dévotion à sainte Anne serait * représentative d'une vision du monde originale qui tente de comprendre et de s'adapter aux 
changements sociaux en conservant sa spécificité ". Comme pour l'économie, on remarque dans le cas des formes hybrides du catholicisme la faiblesse des analyses qui concernent les Autochtones, les anthropologues préférant mettre l'accent sur la mythologie et le chamanisme. En fait, soutient Gagnon, le métissage religieux des Mamit Innuat s'inscrit dans une relation dynamique qui concerne autant le sacré que le social : sainte Anne "permet de valider l'importance de la grand-mère en tant que pôle de la famille étendue et multigénérationnelle, et l'attribution de ce statut lui confère un puissant potentiel de guérison, de régénération et de revitalisation ". Jouant aujourd'hui un rôle central pour apaiser les problèmes sociaux liés à la sédentarisation (drogue, alcoolisme, suicide, agressions sexuelles), la dévotion à sainte Anne témoigne donc d'une hybridité nécessaire à la compréhension même de la modernité.

En passant en revue les différentes initiatives qui permettent la participation des Cris de la Baie-James à la gestion de l'exploitation forestière, Françoise Lathoud cherche à mesurer le décalage qui existe entre les propositions légales et administratives et leurs applications réelles dans les communautés. Lathoud remarque que, de manière générale, la participation des Autochtones au processus de développement et de transformation de leurs territoires augmente de manière constante depuis les années 1970, mais que cette "participation "varie selon les traités et les situations, allant d'une simple consultation à la cogestion véritable. Aussi, de plus grands pouvoirs " au niveau de la juridiction et des structures de gestion "sont nécessaires, mais insuffisants si on ne prend pas en compte "la diversité culturelle " qui doit déboucher sur des solutions alternatives de communication et de décision. Une fois encore, l'économie, la vie en société et la coexistence ne peuvent être séparées de considérations culturelles dans l'émergence des modernités.

Par * un examen systématique de la relation qui lie les institutions traditionnelles et modernes "et non seulement par l'analyse de ses manifestations, Thibault Martin cherche à comprendre le caractère unique de la modernité inuite contemporaine, tout en se demandant si la combinaison dont elle est issue correspond à une phase transitoire ou, au contraire, à une institutionnalisation de l'hybridité, * entre institutions modernes et traditionnelles •, qui pourrait - donner naissance à une société parfaitement unique et originale dans sa construction de la modernité . Étudiant l'exemple du " congélateur communal * instauré par le Programme d'aide aux chasseurs, à mi-chemin entre le don et le système 
de répartition de la richesse, Martin constate que les institutions traditionnelles "jouent un rôle spécifique qui n'est pas dichotomique mais parfois complémentaire à celui des institutions modernes ": " $\mathrm{Si}$ bien que rien ne permet d'affirmer que les institutions modernes vont lentement se substituer aux traditionnelles *. Il s'agirait, dans le cas des Inuits, d'une modernité hybride, réflexive et "en partie le fruit de l'action sociale et donc des choix des membres de la communauté w.

Envisager les modernités amérindiennes et inuite conduit ainsi à imaginer de toutes nouvelles formes de gestion du territoire, de la société, des pouvoirs et de la culture qui permettent de concevoir une modernité hybride inclusive de la renaissance des modes de vie traditionnels, en fusion avec des éléments du tout récent passé colonial et correspondant à un besoin contemporain d'identification, d'adaptabilité et de développement culturel et social. 